\title{
Denosumab compared to bisphosphonates to treat postmenopausal osteoporosis: a meta-analysis
}

\author{
Jiaqi Wu, Qingsheng Zhang, Guanghui Yan and Xianhui Jin ${ }^{*}$
}

\begin{abstract}
Background: The standard treatment for osteoporosis was controversial. Denosumab and bisphosphonates were two most common drugs. The purpose of this study was to compare the efficacy and safety of denosumab with bisphosphonates to treat osteoporosis.

Methods: Published literatures, only including randomized controlled trials (RCTs), were searched in the following electronic databases: PubMed, Embase, Web of Science, Cochrane Library, and Google database from inception to April 20 2018. Studies that compared denosumab with bisphosphonates to treat osteoporosis were included. Random-effect model was used for meta-analysis due to the unavoidable clinical heterogeneity. We used the risk of fracture as the primary outcome. Stata 12.0 was used for meta-analysis.

Results: Eleven studies involving 5446 patients (denosumab $=2873$, bisphosphonates $=2573$ ) were included in the present meta-analysis. There was no significant difference between the risk of fracture (risk ratio (RR), 1.13; 95\% confidence interval $(\mathrm{Cl}), 0.82-1.55 ; P=0.466)$, adverse events (AEs) (RR 1.00; 95\% Cl 0.96-1.04; $P=0.957$ ) and withdrawn due to AEs (RR 0.68; 95\% Cl 0.34-137; $P=0.280$ ). Denosumab compared with bisphosphonates significantly increased change in total hip, femoral neck, lumbar spine, and one-third radius bone mineral density (BMD) for postmenopausal osteoporosis patients $(P<0.05)$.

Conclusions: Our meta-analysis suggested that denosumab but not bisphosphonates significantly increased change in total hip, femoral neck, lumbar spine, and one-third radius BMD for postmenopausal osteoporosis patients. Current evidence suggested no benefit of denosumab for reducing risk of fracture than bisphosphonates. More long-term follow-up RCTs are needed to identify the potential complications of denosumab.
\end{abstract}

Keywords: Denosumab, Bisphosphonates, Fracture, Meta-analysis

\section{Background}

Osteoporosis (OP) is a common contributor to hip and spine fractures in worldwide patients $[1,2]$. OP is a global public health problem and affects appropriately 75 million people in the USA [3]. The ideal therapeutic goal is to increase the bone mass, and subsequently decrease the risk of fracture [4]. Bisphosphonates, a classic antiresorptive agent, is currently the most common therapy for osteoporosis [5]. However, compliance was the major concern of bisphosphonates [6]. Prolonged medication and possible complications limited the effects of bisphosphonates for OP patients.

\footnotetext{
* Correspondence: 2593463778@qq.com

The Second Department of Orthepaedics, Harrison International Peace

Hospital, No. 180 Renmin East Road, Hengshui 053000, Hebei, China
}

Receptor activator of nuclear factor-kB ligand (RANKL) is a cytokine that is essential for osteoclast survival and differentiation. Thus, through blocking the RANKL could inhibit the differentiation of osteoclast and increase the bone mass. Denosumab, a fully human monoclonal antibody against the RANKL, could potently reduce bone resorption with accompanying increases in bone mineral density (BMD). Denosumab $60 \mathrm{mg}$ was always subcutaneously given per 6 months and thus the compliances may be well. Previously, a meta-analysis that compared denosumab with bisphosphonates for OP patients has been published [7]. However, several disadvantages existed in the meta-analysis. (1) Only four randomized controlled trials (RCTs) were included and the sample was relatively

(c) The Author(s). 2018 Open Access This article is distributed under the terms of the Creative Commons Attribution 4.0 International License (http://creativecommons.org/licenses/by/4.0/), which permits unrestricted use, distribution, and 
small. (2) They only compared with alendronate, but neglect other bisphosphonates. With new evidence emerging, we performed a meta-analysis that compares denosumab with bisphosphonates for bone loss in postmenopausal osteoporosis patients. We hypothesized that denosumab was superior than bisphosphonates in reducing bone loss in postmenopausal osteoporosis patients and thus reduce the risk of fracture.

\section{Methods}

The present meta-analysis was performed according to the Preferred Reporting Items for Systematic Reviews and Meta-Analyses statement (PRISRMA) [8].

\section{Search strategy}

Published literatures, only including RCTs, were searched in the following electronic databases: PubMed, Embase, Web of Science, Cochrane Library, and Google database from inception to April 20 2018. The keywords and corresponding Mesh terms of osteoporosis and denosumab were referred to published meta-analysis [9]. The keywords and corresponding Mesh term of bisphosphonates was referred to Lou's protocol [10]. Detailed search keywords and Mesh terms can be seen in Additional file 1. Besides, references of all included articles were also reviewed. There was no language limited and no publication restriction.

\section{Inclusion criteria and exclusion criteria Inclusion criteria}

Candidate articles would be included if they met the following criteria: (i) population: patients were diagnosed with osteoporosis and did not take other oral anti-osteoporosis drugs; (ii) intervention: subcutaneously administered denosumab $60 \mathrm{mg}$ per 6 months; (iii) comparison: administration with bisphosphonates, regardless of the dose and intervals; (iv) with one or more of the outcomes described below: risk of fracture, total adverse events (AEs), withdrawn due to AEs, change in one-third radius BMD, change in total hip $\mathrm{BMD}$, change in lumbar spine BMD, and change in femoral neck BMD; and (v) study design: RCTs.

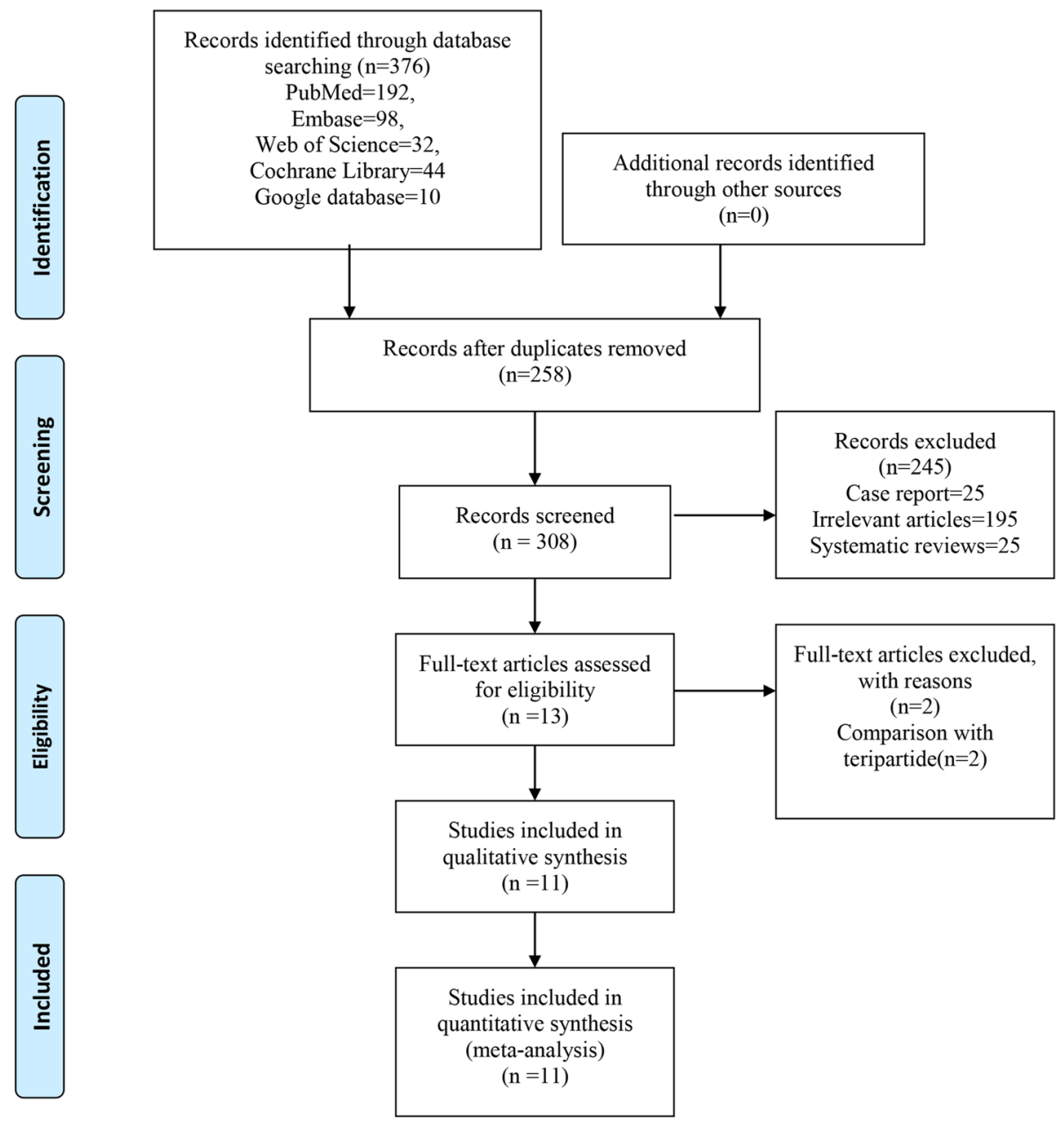

Fig. 1 Flow of trials through the meta-analysis 
Table 1 The general characteristic of the included RCTs

\begin{tabular}{|c|c|c|c|c|c|c|c|c|c|c|}
\hline \multirow[t]{2}{*}{ Author } & \multicolumn{3}{|c|}{ Sample $(n)$} & \multicolumn{2}{|c|}{ Mean age (year) } & \multirow[t]{2}{*}{ Intervention } & \multirow[t]{2}{*}{ Comparison } & \multirow{2}{*}{$\begin{array}{l}\text { Duration } \\
\text { (month) }\end{array}$} & \multirow[t]{2}{*}{ Outcomes } & \multirow[t]{2}{*}{ Study } \\
\hline & Country & Intervention & Comparison & Intervention & Comparison & & & & & \\
\hline $\begin{array}{l}\text { Beck } \\
2008 \text { [11] }\end{array}$ & USA & 39 & 38 & 63 & 63 & $\begin{array}{l}\text { Sc denosumab } \\
\text { injections } \\
\text { (60 mg Q6M) }\end{array}$ & $\begin{array}{l}\text { Oral alendronate } \\
70 \text { mg once weekly }\end{array}$ & 24 & 56 & RCTs \\
\hline $\begin{array}{l}\text { Lewiecki } \\
2007[12]\end{array}$ & USA & 319 & 47 & 62.3 & 62.8 & $\begin{array}{l}\text { Sc denosumab } \\
\text { injections } \\
\text { (60 mg Q6M) }\end{array}$ & $\begin{array}{l}\text { Oral alendronate } \\
70 \text { mg once weekly }\end{array}$ & 24 & 1 & RCTs \\
\hline $\begin{array}{l}\text { McClung } \\
2006 \text { [13] }\end{array}$ & USA & 47 & 47 & 63.1 & 62.8 & $\begin{array}{l}\text { Sc denosumab } \\
\text { injections } \\
\text { (60 mg Q6M) }\end{array}$ & $\begin{array}{l}\text { Oral alendronate } \\
70 \text { mg once weekly }\end{array}$ & 12 & 123,467 & RCTs \\
\hline $\begin{array}{l}\text { Brown } \\
2009[14]\end{array}$ & Spain & 594 & 595 & 64.1 & 64.6 & $\begin{array}{l}\text { Sc denosumab } \\
\text { injections } \\
\text { (60 mg Q6M) }\end{array}$ & $\begin{array}{l}\text { Oral alendronate } \\
70 \text { mg once weekly }\end{array}$ & 12 & $1,234,567$ & RCTs \\
\hline $\begin{array}{l}\text { Kendler } \\
2010[15]\end{array}$ & USA & 253 & 251 & 66.9 & 68.2 & $\begin{array}{l}\text { Sc denosumab } \\
\text { injections } \\
\text { (60 mg Q6M) }\end{array}$ & $\begin{array}{l}\text { Oral alendronate } \\
70 \text { mg once weekly }\end{array}$ & 12 & 234,567 & RCTs \\
\hline $\begin{array}{l}\text { Freemantle } \\
2012 \text { [16] }\end{array}$ & UK & 126 & 124 & 65.1 & 65.3 & $\begin{array}{l}\text { Sc denosumab } \\
\text { injections } \\
\text { (60 mg Q6M) }\end{array}$ & $\begin{array}{l}\text { Oral alendronate } \\
70 \text { mg once weekly }\end{array}$ & 24 & 2345 & RCTs \\
\hline $\begin{array}{l}\text { Kendler } \\
2011[17]\end{array}$ & Canada & 253 & 251 & 66.9 & 68.2 & $\begin{array}{l}\text { Sc denosumab } \\
\text { injections } \\
\text { (60 mg Q6M) }\end{array}$ & $\begin{array}{l}\text { Oral alendronate } \\
70 \text { mg once weekly }\end{array}$ & 12 & 56 & RCTs \\
\hline $\begin{array}{l}\text { Recknor } \\
2013 \text { [18] }\end{array}$ & USA & 417 & 416 & 67.2 & 66.2 & $\begin{array}{l}\text { Sc denosumab } \\
\text { injections } \\
\text { (60 mg Q6M) }\end{array}$ & $\begin{array}{l}\text { Oral ibandronate } \\
150 \text { mg once month }\end{array}$ & 12 & 12,346 & RCTs \\
\hline $\begin{array}{l}\text { Roux } \\
2014 \text { [19] }\end{array}$ & France & 422 & 402 & 67.8 & 67.7 & $\begin{array}{l}\text { Sc denosumab } \\
\text { injections } \\
\text { (60 mg Q6M) }\end{array}$ & $\begin{array}{l}\text { Oral risedronate } \\
150 \text { mg once month }\end{array}$ & 12 & 123,456 & RCTs \\
\hline $\begin{array}{l}\text { Miller } \\
2016 \text { [20] }\end{array}$ & USA & 320 & 320 & 65.9 & 66.1 & $\begin{array}{l}\text { Sc denosumab } \\
\text { injections } \\
\text { (60 mg Q6M) }\end{array}$ & $\begin{array}{l}\text { intravenous } \\
\text { zoledronic acid } \\
5 \mathrm{mg} \text { once year }\end{array}$ & 12 & 123,457 & RCTs \\
\hline $\begin{array}{l}\text { Seeman } \\
2010[21]\end{array}$ & Australia & 83 & 82 & 60.3 & 60.7 & $\begin{array}{l}\text { Sc denosumab } \\
\text { injections } \\
\text { (60 mg Q6M) }\end{array}$ & $\begin{array}{l}\text { oral alendronate } \\
70 \text { mg once weekly }\end{array}$ & 12 & 23 & RCTs \\
\hline
\end{tabular}

1, risk of fracture; 2 , AEs, 3 withdrawn due to AEs; 4, change in total hip BMD; 5, change in femoral neck BMD; 6, change in lumbar spine BMD; 7, change in one-third radius $\mathrm{BMD}$

\section{Exclusion criteria}

Candidate articles would be excluded if they met the following criteria: (i) patients were diagnosed with other type of osteoporosis (androgen-deprivation therapy or breast cancer); (ii) intervention: combined denosumab with other drugs; and (iii) non-RCTs.

\section{Assessment of study quality}

Two reviewers (Jiaqi Wu and Qingsheng Zhang) independently assessed the quality of RCTs in accordance with Cochrane Collaboration's tool for assessing the risk of bias. If there was conflict between the two reviewers, a third reviewer is consulted and they discussed to solve the controversy. The tool included the following items: random sequence generation, allocation concealment, blinding, incomplete outcome data, and selective outcome reporting. We further performed Kappa test to increase the stability of our meta-analysis.

\section{Data extraction}

Two reviewers independently extracted the following data and written in a pre-generated Excel file: first author's name, publication year, mean age, intervention, comparison, outcomes, and duration. First outcome was the risk of fracture, since fracture has a heavy economic burden to the society and patients. Second outcomes were change in one-third radius BMD, change in total hip BMD, change in lumbar spine BMD, and change in femoral neck BMD. Safety outcomes included total AEs, withdrawn due to AEs.

\section{Statistical analysis}

In consideration of the clinical heterogeneity, we used random-effect model for all of the outcomes. Outcomes were divided into two categories (dichotomous data and continuous data). Dichotomous data were expressed as proportions, such as risk of fracture, AEs, and withdrawn due to 
AEs; the intervention effect was expressed as a risk ratio (RR) and corresponding confidence intervals (CI). Continuous data were meta-analyzed in terms of the weighted mean difference (WMD) and associated 95\% CI. Publication bias was assessed by funnel plot, Begg's test, and Egger's test. Subgroup analysis was performed according to the comparator treatment, population who had been prescribed a treatment for osteoporosis and high or unclear risk of bias.

Pooled data were assessed for heterogeneity using the $I^{2}$ tests. Heterogeneity was defined as absent when $I^{2}$ was between 0 and 25\%; low, between 25.1 and 50\%; moderate, between 50.1 and 75\%; or high, between 75.1 and $100 \%$.

\section{Result}

Search results

Systematic search of PubMed, Embase, Web of Science, Cochrane Library, and Google database turned up 376 potentially eligible studies, and no additional records were found during manual searches of reference lists. After removing 118 duplicate studies using Endnote X7, another 245 studies were excluded based on their titles and abstracts. The remaining 13 studies were read in full, and 2 were excluded because they failed to satisfy the selection criteria. In the end, 11 RCTs involving 5446 patients $($ denosumab $=2873$, bisphosphonates $=2573)[11-21]$ were included in the systematic review and meta-analysis. Details of study identification, screening, and selection are given in Fig. 1.

\section{Characteristics of included studies}

The publication years were raged from the year of 2006 to 2016. Altogether involving 5449 cases of osteoporosis. Six studies were performed in the USA, 1 in Spain, 1 in UK, 2 in Canada, and 1 France and 1 Australia. The dose of denosumab was administration with subcutaneous injection $60 \mathrm{mg}$ every 6 months. We included four types of bisphosphonates (alendronate, ibandronate, risedronate, and zoledronic acid). The duration of follow-up was ranged from 12 to 24 months. Detailed information of the characteristic can be obtained in Table 1 .

\section{Quality of the included RCTs}

Details of the risk of bias are summarized in Figs. 2 and 3. Overall, ten trials were categorized as at low risk of bias, one as being unclear, and none being at high risk of bias. Only one study did not introduce the random sequence generation and thus categorized as unclear risk of bias. Since we did not know whether the funding institution participated into the experimentation and thus all of the other bias was categorized as unclear risk of bias.

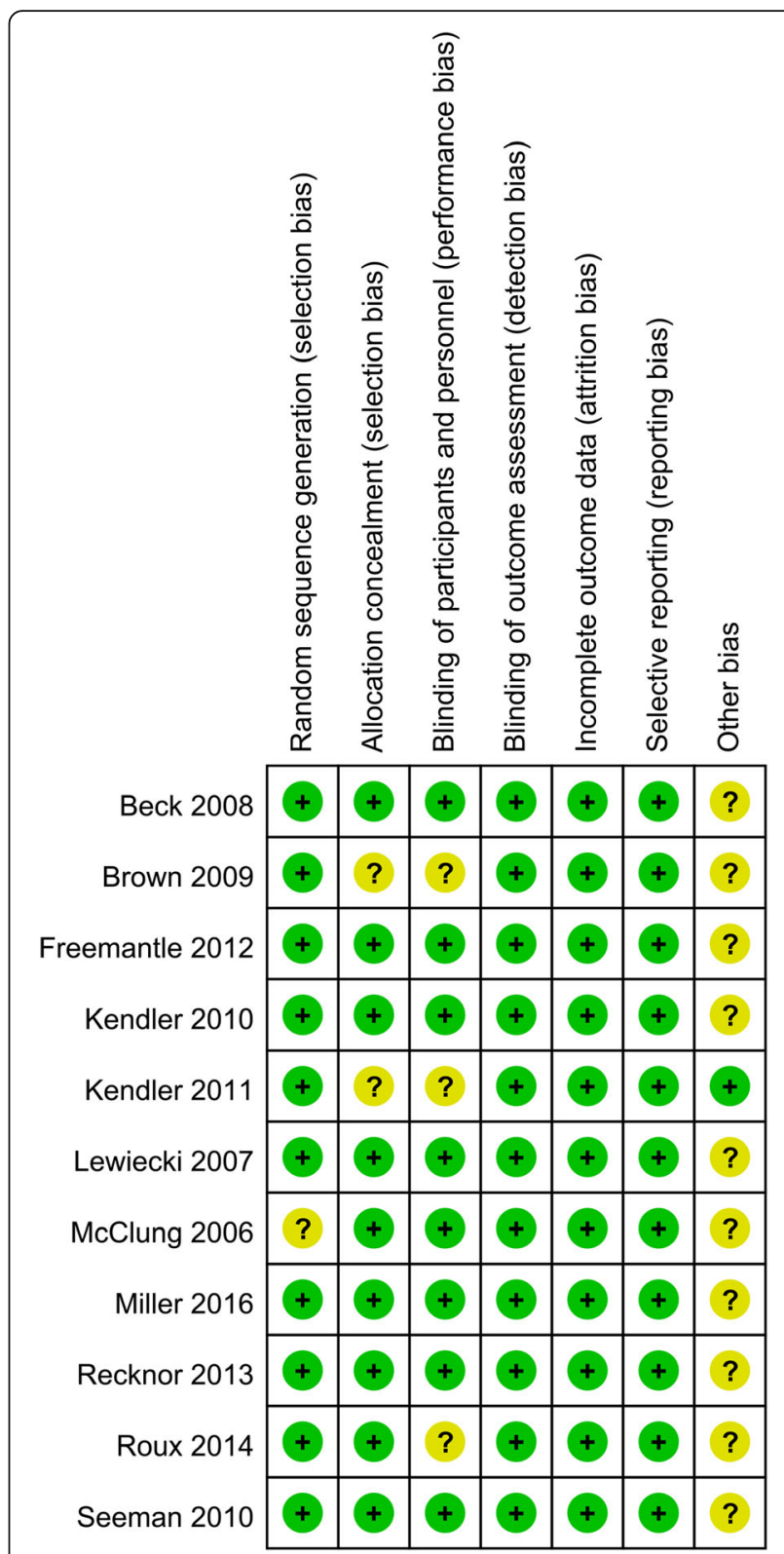

Fig. 2 The risk of bias summary, +, no bias; -, bias;?, bias unknown

\section{Results of meta-analysis} Risk of fracture

Six trials totaling 4218 patients provided data on risk of fracture. Compared with bisphosphonates treatment, administration with denosumab has no benefit for reducing the risk of fracture (RR 1.13; 95\% CI 0.82-1.55; $P=0.466)$ (Fig. 4$)$, with no heterogeneity $\left(I^{2}=0.0 \%\right)$. For the meta-analysis of denosumab versus bisphosphonates on risk of fracture, there was no evidence of publication bias by inspection of the funnel plot (Fig. 5) and formal statistical tests (Egger test, $P=0.85$; Begg test, $P=0.69$ ) (Figs. 6 and 7). To further increase the persuasion of this 


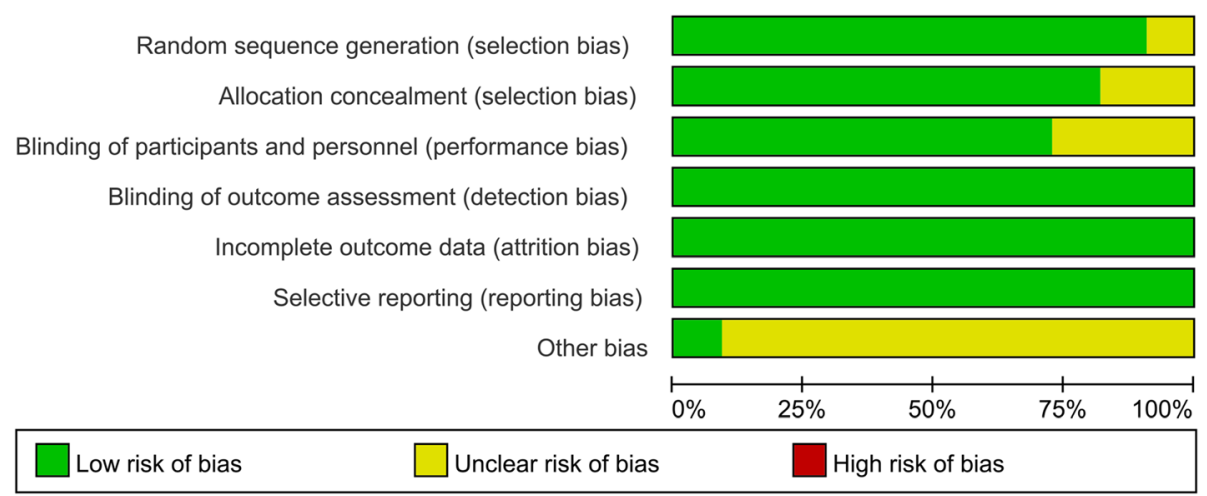

Fig. 3 Risk of bias of graph of the included randomized controlled trials

outcome, we performed a sensitivity analysis using leave out one study in turn and results shown that after leaving out one study in turn, the overall effect size was not changeable (Fig. 8).

Table 2 presents the results of subgroup analyses. The findings of decreased risk of fracture were consistent in all subgroup analyses.

\section{AEs}

Seven trials totaling 4776 patients provided data on AEs. There was no significant difference between denosumab and bisphosphonates in terms of the AEs (RR 1.00; 95\% CI 0.961.04; $P=0.957$ ) (Fig. 9), with little heterogeneity $\left(I^{2}=14.6 \%\right)$.

\section{Withdrawn due to AEs}

Eight trials totaling 4816 patients provided data on withdrawn due to AEs. There was no significant difference between denosumab and bisphosphonates in terms of the withdrawn due to AEs (RR 0.68; 95\% CI 0.34-137; $P=$ 0.280 ) (Fig. 10), with middle heterogeneity $\left(I^{2}=50.8 \%\right)$.

\section{Change in total hip BMD}

Compared with bisphosphonates, denosumab for osteoporosis patients further increased change in total hip BMD (MD 1.05\%; 95\% CI 0.85 to $1.26 ; P=0.000$, Fig. 11 ) with middle heterogeneity $\left(I^{2}=31.4 \%\right)$.

\section{Change in femoral neck BMD}

Compared with bisphosphonates, denosumab for osteoporosis patients further increased change in femoral neck BMD, $(\mathrm{WMD}=1.06 \%$; $95 \% \mathrm{CI} 0.79$ to $1.32 ; P=$ 0.000 , Fig. 12) with middle heterogeneity $\left(I^{2}=30.5 \%\right)$.

\section{Change in lumbar spine BMD}

Compared with bisphosphonates, denosumab for osteoporosis patients further increased change in lumbar

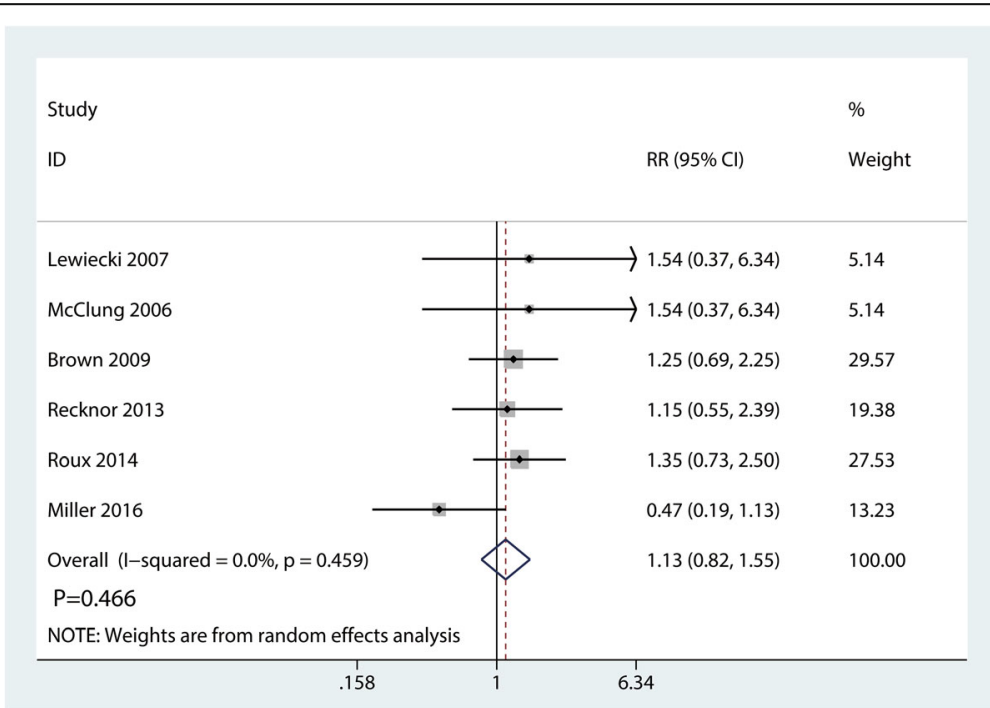

Fig. 4 Forest plots of the included studies comparing the risk of fracture 


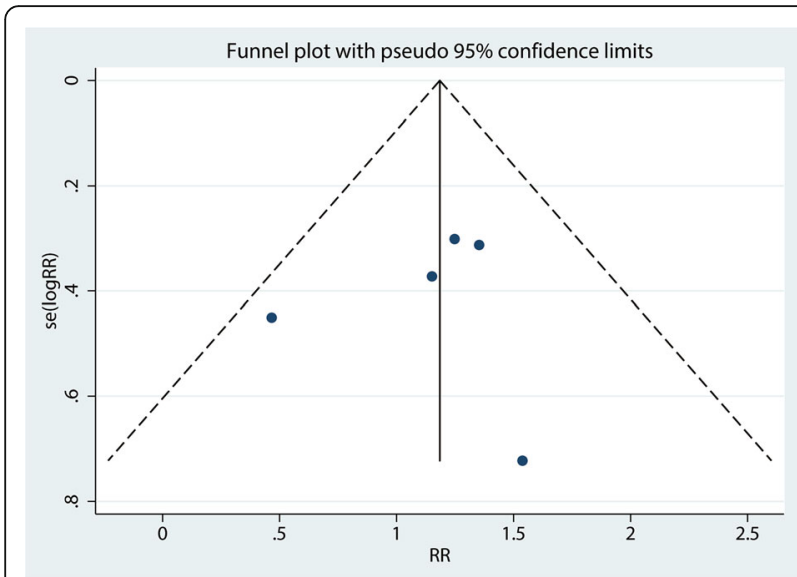

Fig. 5 Funnel plot of the risk of fracture

spine BMD (WMD $=1.55 \%$; $95 \%$ CI 1.09 to $2.02 ; P=$ 0.000 , Fig. 13) with high heterogeneity $\left(I^{2}=72.2 \%\right)$.

\section{Change in one-third radius BMD}

Compared with bisphosphonates, denosumab for osteoporosis patients further increased change in one-third radius $\mathrm{BMD}$ (WMD $=0.83 \%$; $95 \% \mathrm{CI} 0.34$ to $1.31 ; P=$ 0.000 , Fig. 14) with high heterogeneity $\left(I^{2}=61.1 \%\right)$.

\section{Discussion}

Our meta-analysis comprehensively and systematically reviewed the current available literature and found that (1) denosumab compared with bisphosphonates significantly increased change in total hip, femoral neck, lumbar spine, and one-third radius BMD for postmenopausal osteoporosis patients. The evidence of benefit was consistent when we further performed a sensitivity analysis; (2) denosumab has no benefit for reducing the risk of fracture when compared with bisphosphonates; (3) and the occurrence of AEs and withdrawn due to AEs were similar in denosumab and bisphosphonates.

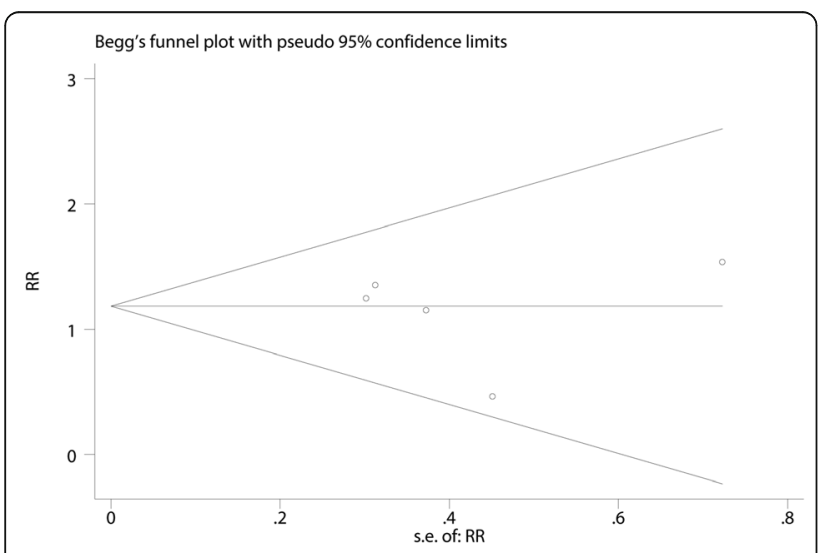

Fig. 6 Egger test for risk of fracture

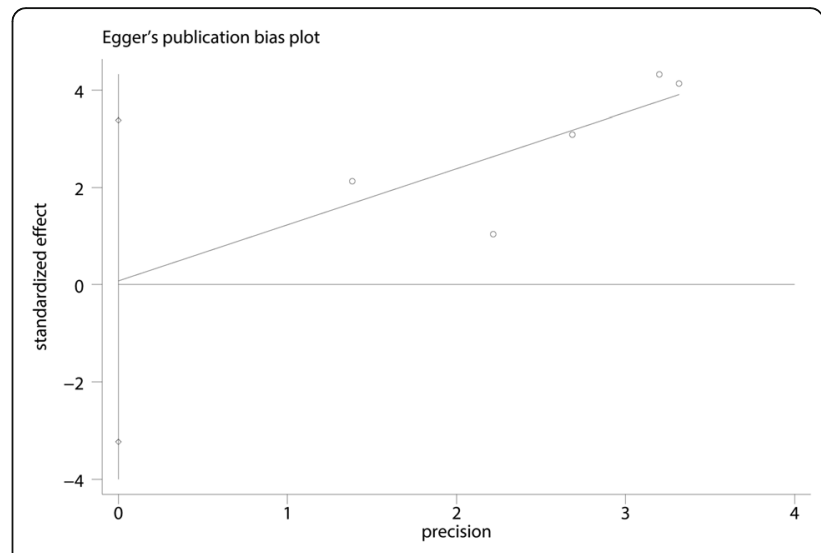

Fig. 7 Begg's test for risk of fracture

Several meta-analyses on the topic have been published [7, 9]. However, differences between current meta-analysis and the previous ones should be noted. First, these previous meta-analyses identified other anti-osteoporosis drugs (teriparatide) and placebo as comparison. Therefore, a large heterogeneity existed in previous meta-analyses. Second, several literatures were left out in previous meta-analyses and thus potential publication bias existed in their study. Beaudoin et al. [9] compared denosumab with other treatments to prevent or treat osteoporosis. We noted that they included patients that prescribed daily or weekly bisphosphonate therapy $\geq 1$ month. Thus, we could not determine the real effects of denosumab for postmenopausal osteoporosis. Lin et al. [7] conducted a meta-analysis that compared denosumab and alendronate in postmenopausal women with osteoporosis. However, only four heterogeneous RCTs were included. Current meta-analysis added statistical power of at least 7 RCTs and appropriately 1900 cases. In summary, our current meta-analysis was the latest and the most comprehensive one.

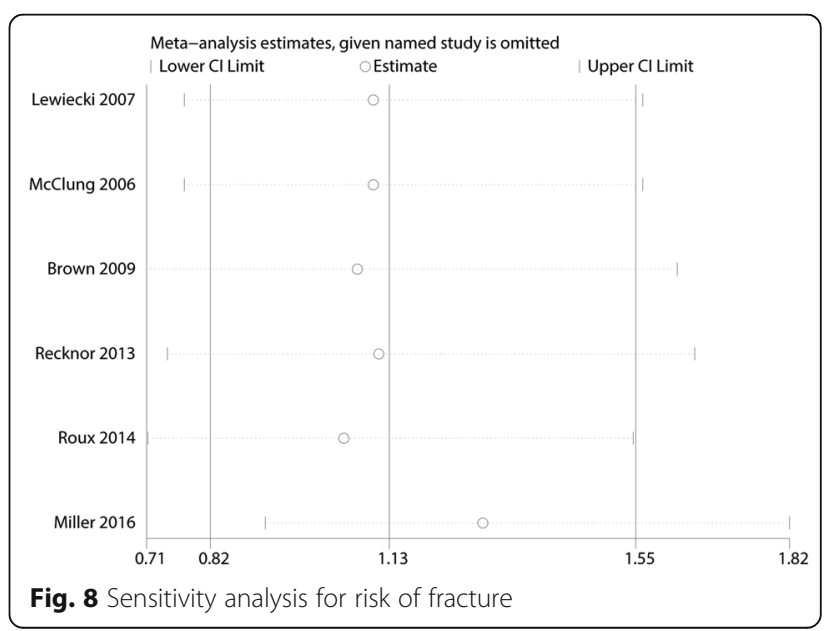


Table 2 Subgroup analysis of the risk of fracture

\begin{tabular}{|c|c|c|c|}
\hline Subgroup & No. of included studies & $\mathrm{RR}(95 \% \mathrm{Cl})$ & $P^{2}(\%)$ \\
\hline \multicolumn{4}{|c|}{ Comparator treatment } \\
\hline Alendronate & 3 & $1.10(0.95,1.23)$ & 12.3 \\
\hline Ibandronate & 1 & $1.08(0.89,1.16)$ & - \\
\hline Risedronate & 1 & $1.23(0.75,1.08)$ & - \\
\hline Zoledronic acid & 1 & $0.86(0.74,0.99)$ & - \\
\hline \multicolumn{4}{|c|}{ Population who had been prescribed a treatment for osteoporosis } \\
\hline $\begin{array}{l}\text { No }(<100 \% \text { of } \\
\text { participants) }\end{array}$ & 4 & $1.15(0.67,1.22)$ & 0.0 \\
\hline $\begin{array}{l}\text { No (> 100\% of } \\
\text { participants) }\end{array}$ & 3 & $1.12(0.85,1.08)$ & 0.0 \\
\hline \multicolumn{4}{|c|}{ High or unclear risk of bias } \\
\hline No & 2 & $1.09(0.74,1.26)$ & 0.0 \\
\hline Yes & 5 & $1.31(0.89,1.14)$ & 0.0 \\
\hline
\end{tabular}

The difference between denosumab and bisphosphonates for clinical outcomes were change in the skeletal BMD. Denosumab has a greater antiresorptive effect than bisphosphonates. The effects of bisphosphonates for preventing bone loss mainly need bisphosphonates binding to bone mineral. Denosumab mainly through direct combined with the RANKL and inhibit the survival and differentiation of osteoclast. In general, increasing of the BMD means a decrease in the occurrence of fracture. However, we did not observe any significant difference between the risk of fracture. The reason may be as follows: (1) gain in BMD over a relatively short time was not enough to reduce the risk of fracture, and (2) the occurrence of fracture was affected by many factors. Murad et al. [22] conducted a network meta-analysis and compared with different drugs for

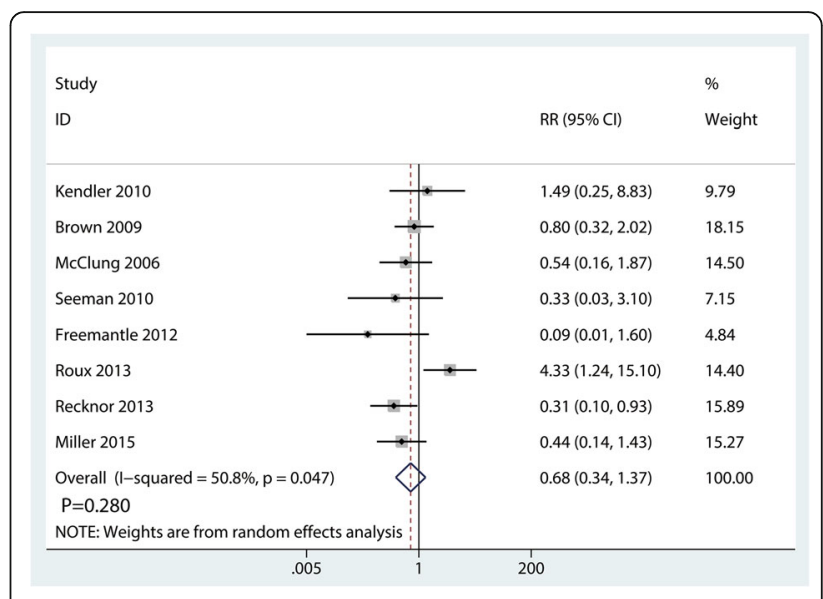

Fig. 10 Forest plots of the included studies comparing the withdrawn due to AEs preventing fragility fractures. Results show that teriparatide, bisphosphonates, and denosumab are the most effective in reducing the risk of fragility fractures.

When a new drug was popularized and applied in clinical trials, AEs were the major concern. In current meta-analysis, we compared total AEs and withdrawn due to AEs. Results show that there was no significant difference between the total AEs and withdrawn due to AEs. Since immune cells also have the RANKL receptor and the major concern was the denosumab for immune function. Later, Stolina et al. [23] and Bekker et al. [24] suggest that denosumab has no effects on RANKL/ RANK pathway in immune system.

Our meta-analysis also had limitations. (1) Included studies were sponsored by drug dealer and thus may resulted in performance bias. (2) We included osteoporosis

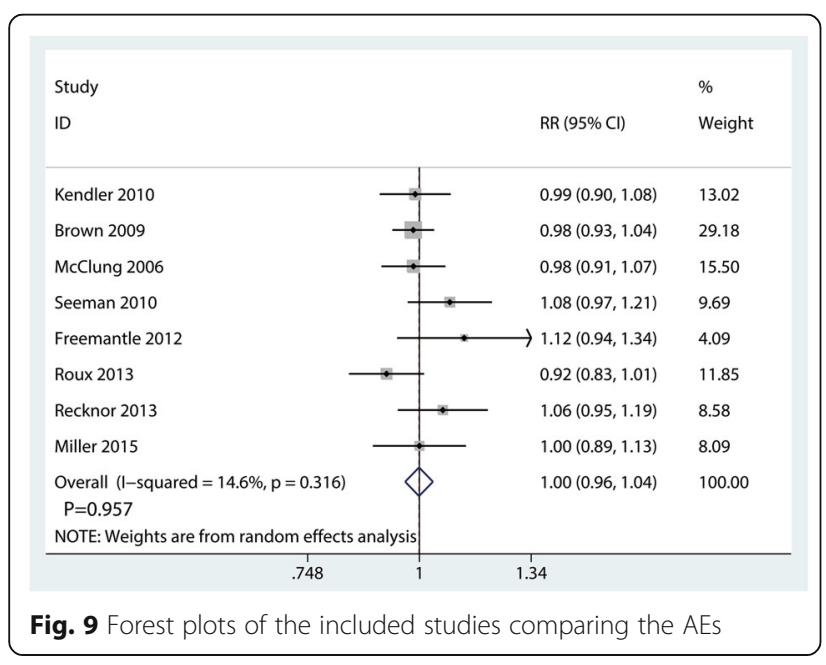

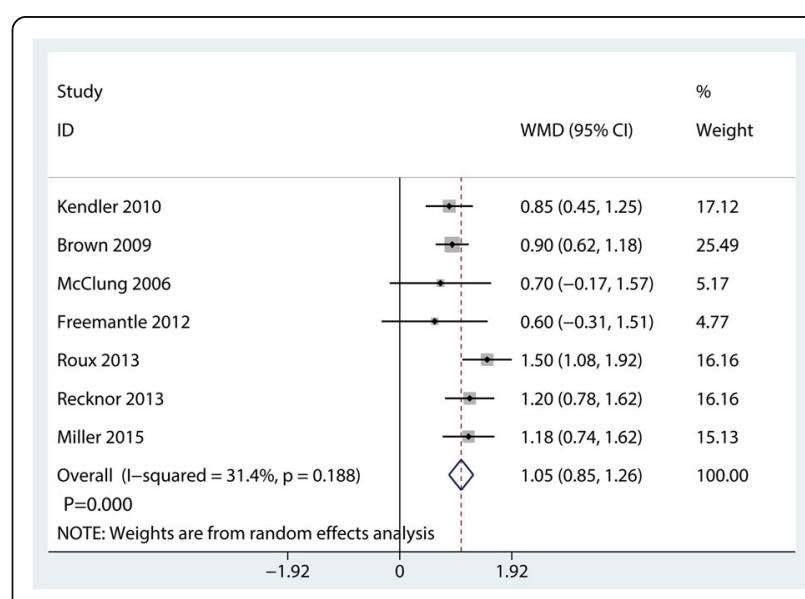

Fig. 11 Forest plots of the included studies comparing the change in total hip BMD 


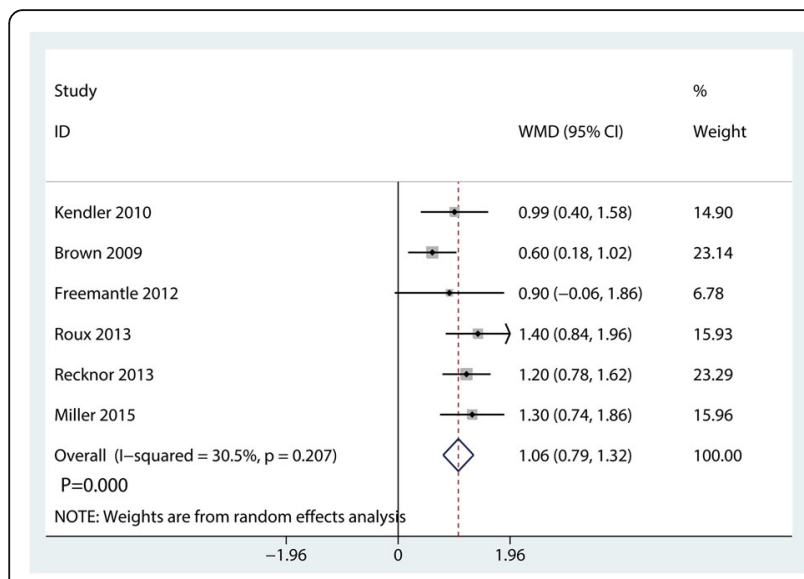

Fig. 12 Forest plots of the included studies comparing the change in femoral neck BMD

patients that came from different countries and with different diagnostic criteria. Thus, the clinical heterogeneity was imminent. (3) Duration of follow-up was relatively short in the included studies and thus some severe complications were underestimated.

\section{Conclusion}

Our meta-analysis suggested that denosumab but not bisphosphonates significantly increased change in total hip, femoral neck, lumbar spine, and one-third radius BMD for postmenopausal osteoporosis patients. Current evidence suggested no benefit of denosumab for reducing risk of fracture than bisphosphonates. More long-term follow-up RCTs are needed to identify the potential complications of denosumab.

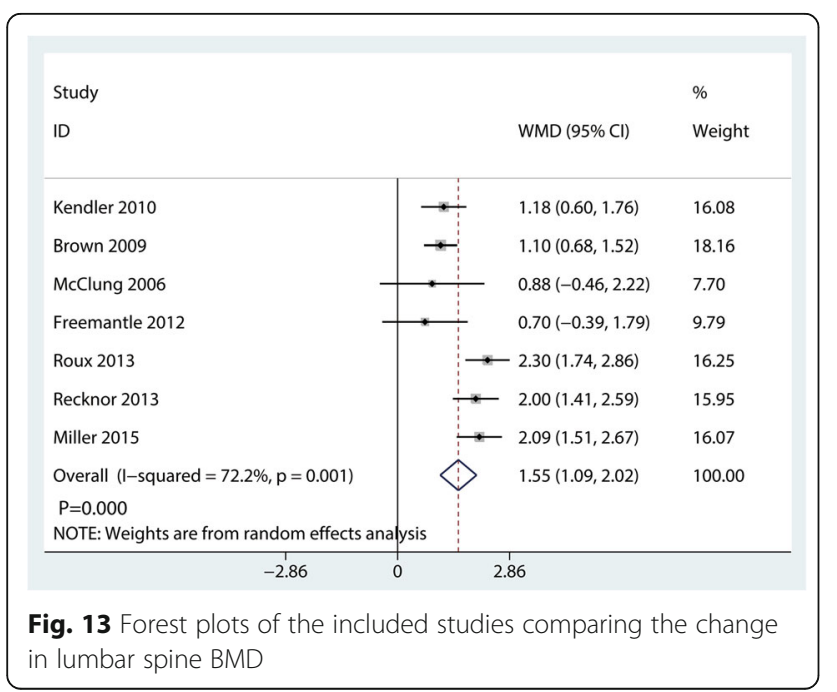

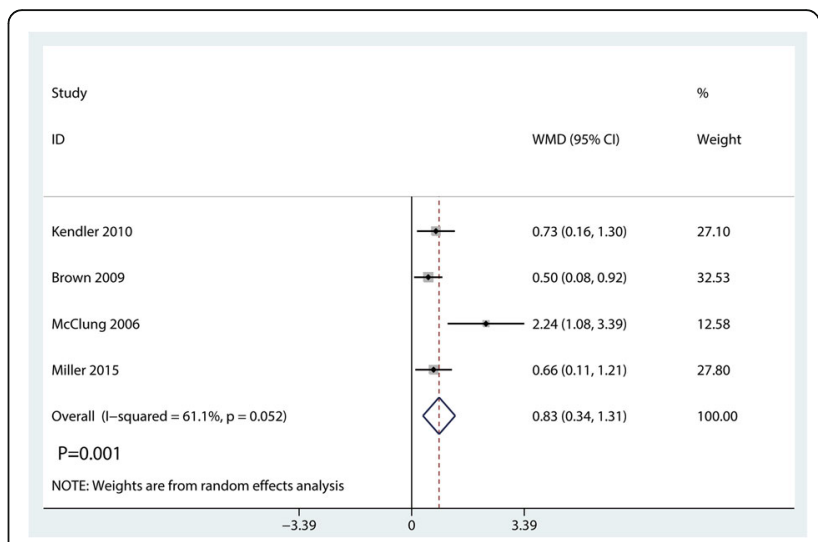

Fig. 14 Forest plots of the included studies comparing the change in one-third radius BMD

\section{Additional file}

Additional file 1: Detailed search keywords and Mesh terms in PubMed database. (DOCX $14 \mathrm{~kb}$ )

\section{Abbreviation}

AEs: Adverse events; BMD: Bone mineral density; Cl: Confidence intervals; OP: Osteoporosis; RANKL: Receptor activator of nuclear factor-kB ligand; RCTs: Randomized controlled trials; RR: Risk ratio; WMD: Weighted mean difference

Availability of data and materials

Supporting data is available.

\section{Authors' contributions}

JQW designed the study and developed the retrieve strategy. QSZ and GHY searched and screened the summaries and titles. JQW and XHJ drafted the article. All authors read and approved the final draft.

\section{Ethics approval and consent to participate}

This is a meta-analysis; no relative problems exist.

\section{Consent for publication}

Not applicable.

\section{Competing interests}

The authors declare that they have no competing interests.

\section{Publisher's Note}

Springer Nature remains neutral with regard to jurisdictional claims in published maps and institutional affiliations.

Received: 20 April 2018 Accepted: 14 June 2018

Published online: 02 August 2018

\section{References}

1. Siris ES, et al. The clinical diagnosis of osteoporosis: a position statement from the National Bone Health Alliance Working Group. Osteoporos Int. 2014;25(5):1439-43.

2. Liu W, et al. Meta-analysis of osteoporosis: fracture risks, medication and treatment. Minerva Med. 2015:106(4):203-14.

3. Maghbooli Z, et al. Negative correlation of high-density of lipoproteincholesterol and bone mineral density in postmenopausal Iranian women with vitamin D deficiency. Menopause. 2018. https://doi.org/10.1097/GME. 0000000000001082.

4. Fujiwara $\mathrm{S}$, et al. Treatment patterns in patients with osteoporosis at high risk of fracture in Japan: retrospective chart review. Arch Osteoporos. 2018; 13(1):34. 
5. Buerba RA, et al. Bisphosphonate and Teriparatide use in thoracolumbar spinal fusion: a systematic review and meta-analysis of comparative studies. Spine (Phila Pa 1976). 2018. https://doi.org/10.1097/BRS.0000000000002608.

6. Saito T, et al. Effectiveness of anti-osteoporotic drugs to prevent secondary fragility fractures: systematic review and meta-analysis. Osteoporos Int. 2017; 28(12):3289-300.

7. Lin T, et al. Comparison of clinical efficacy and safety between denosumab and alendronate in postmenopausal women with osteoporosis: a metaanalysis. Int J Clin Pract. 2012;66(4):399-408.

8. Liberati $A$, et al. The PRISMA statement for reporting systematic reviews and meta-analyses of studies that evaluate healthcare interventions: explanation and elaboration. Bmj. 2009;339:b2700

9. Beaudoin $C$, et al. Denosumab compared to other treatments to prevent or treat osteoporosis in individuals at risk of fracture: a systematic review and meta-analysis. Osteoporos Int. 2016;27(9):2835-44.

10. Lou S, et al. Combination therapy of anabolic agents and bisphosphonates on bone mineral density in patients with osteoporosis: a meta-analysis of randomised controlled trials. BMJ Open. 2018;8(3):e015187.

11. Beck TJ, et al. Effects of denosumab on the geometry of the proximal femur in postmenopausal women in comparison with alendronate. J Clin Densitom. 2008;11(3):351-9.

12. Lewiecki EM, et al. Two-year treatment with denosumab (AMG 162) in a randomized phase 2 study of postmenopausal women with low BMD. J Bone Miner Res. 2007:22(12):1832-41.

13. McClung MR, et al. Denosumab in postmenopausal women with low bone mineral density. N Engl J Med. 2006:354(8):821-31.

14. Brown JP, et al. Comparison of the effect of denosumab and alendronate on BMD and biochemical markers of bone turnover in postmenopausal women with low bone mass: a randomized, blinded, phase 3 trial. J Bone Miner Res. 2009;24(1):153-61.

15. Kendler DL, et al. Effects of denosumab on bone mineral density and bone turnover in postmenopausal women transitioning from alendronate therapy. J Bone Miner Res. 2010;25(1):72-81.

16. Freemantle $\mathrm{N}$, et al. Final results of the DAPS (Denosumab adherence preference satisfaction) study: a 24-month, randomized, crossover comparison with alendronate in postmenopausal women. Osteoporos Int. 2012:23(1):317-26.

17. Kendler DL, et al. Adherence, preference, and satisfaction of postmenopausal women taking denosumab or alendronate. Osteoporos Int 2011;22(6):1725-35.

18. Recknor C, et al. Denosumab compared with ibandronate in postmenopausal women previously treated with bisphosphonate therapy: a randomized open-label trial. Obstet Gynecol. 2013;121(6):1291-9.

19. Roux $C$, et al. Denosumab compared with risedronate in postmenopausal women suboptimally adherent to alendronate therapy: efficacy and safety results from a randomized open-label study. Bone. 2014;58:48-54.

20. Miller PD, et al. Denosumab or Zoledronic acid in postmenopausal women with osteoporosis previously treated with oral bisphosphonates. J Clin Endocrinol Metab. 2016;101(8):3163-70.

21. Seeman E, et al. Microarchitectural deterioration of cortical and trabecular bone: differing effects of denosumab and alendronate. J Bone Miner Res. 2010;25(8):1886-94.

22. Murad MH, et al. Clinical review. Comparative effectiveness of drug treatments to prevent fragility fractures: a systematic review and network meta-analysis. J Clin Endocrinol Metab. 2012;97(6):1871-80.

23. Stolina M, et al. RANKL inhibition: from mice to men (and women). Adv Exp Med Biol. 2007:602:143-50.

24. Bekker PJ, et al. A single-dose placebo-controlled study of AMG 162, a fully human monoclonal antibody to RANKL, in postmenopausal women. J Bone Miner Res. 2004;19(7):1059-66.

Ready to submit your research? Choose BMC and benefit from:

- fast, convenient online submission

- thorough peer review by experienced researchers in your field

- rapid publication on acceptance

- support for research data, including large and complex data types

- gold Open Access which fosters wider collaboration and increased citations

- maximum visibility for your research: over $100 \mathrm{M}$ website views per year

At BMC, research is always in progress.

Learn more biomedcentral.com/submissions 